\section{Qualidade da água e fatores de contaminação de poços rasos na área urbana de Anastácio (MS)}

Resumo: Objetivou-se avaliar a qualidade das águas e relacioná-la com as condições de infraestrutura de poços rasos selecionados em cinco setores de Anastácio-MS. A qualidade das águas dos poços foi avaliada pelo Número Mais Provável (NMP.100 $\mathrm{mL}^{-1}$ ) de coliformes totais e fecais (tubos múltiplos); cloreto, dureza total e alcalinidade total (titulométrico), $\mathrm{pH}$ e condutividade elétrica (eletrométrico). As elevadas percentagens de amostras com presença de bactérias, as concentrações de cloretos acima do Valor Máximo Permitido e a condutividade elétrica elevada nas águas podem ter origem na ineficiência do sistema sanitário da cidade e na falta de orientação do poder público referente aos riscos para a saúde da população ao consumir água sem tratamento captada em poços rasos.

\section{Water quality and contamination fators of shallow wells in urban area Anastácio - MS}

\footnotetext{
Abstract: The objective with this paper was to evaluate the water quality, and relate it to the infrastructure conditions of selected shallow wells in five sectors of Anastacio - State of Mato Grosso do Sul, Brazil. We evaluated the wells' quality of water by the Most Probable Number (NMP.100 mL-1) for total coliforms, and fecal coliforms (both by Multiple Tubes), chloride, total hardness, and total alkalinity (titration), $\mathrm{pH}$, and electrical conductivity (electrometric). The high percentage of samples with presence of bacteria, the chloride concentrations above the Maximum Allowed Value, and high electrical conductivity in water may stem from the inefficiency of the sanitary system of the city, and in the absence of guidance from the public regarding the health risks of the population consuming untreated water captured in shallow wells.
}

Nanci Capp*

Lucy Ribeiro Ayach**

Tânia Mara Baptista dos Santos***

Solange Terezinha de Lima Guimarães****

* Professora Assistente do curso de Zootecnia da Universidade Estadual de Mato Grosso do Sul (UEMS), campus Aquidauana-MS.

** Professora Adjunta do curso de Geografia Universidade Federal de Mato Grosso do Sul (UFMS), campus Aquidauana-MS.

*** Professora Adjunta do curso de Zootecnia da Universidade Estadual de Mato Grosso do Sul (UEMS), campus Aquidauana-MS.

**** Professora Livre Docente da Universidade Estadual Paulista Júlio Mesquisa Filho (UNESP), Rio Claro-SP.

\section{Palavras-chave:}

Água de poço, coliformes, contaminação, fator de proteção.

Key-words:

Well water, coliform, contamination, protection factor. 


\section{Introdução}

A água é indispensável para todos os seres vivos, sendo utilizada para diversas finalidades, especialmente, para a manutenção da vida no planeta. Todavia, nas últimas décadas, o crescimento populacional contribuiu significativamente para a aceleração do crescimento de áreas urbanas, muitas vezes sem quaisquer infraestruturas urbanísticas e de saneamento, e consequentemente, levando a um aumento da demanda por água potável e para outras formas de uso.

A água potável pode ser definida como água para consumo humano cujos parâmetros físicos, químicos, microbiológicos e radioativos atendam ao padrão de potabilidade e não ofereça riscos à saúde, definido pelos valores máximos permissíveis estabelecidos pela Portaria $n^{\circ} 518$ do Ministério da Saúde (BRASIL, 2004), garantindo com segurança, o fornecimento de água tratada de boa qualidade com concentrações mínimas de constituintes, conhecidos por serem perigosos à saúde. (D'AGUILA et al., 2000, p.792).

A concentração de grandes massas populacionais de baixo poder aquisitivo, em áreas urbanas periféricas que apresentam carência ou ineficiência de infraestruturas básicas, também deve ser um aspecto a ser considerado, tendo em vista que nestas áreas observa-se, a geração de práticas inadequadas referentes à disposição do lixo e do esgoto, contribuindo para a contaminação das fontes de água superficiais e subterrâneas.

De acordo com Calheiros e Oliveira (2006, p.1), no Brasil, 80\% dos esgotos são lançados em corpos d'água sem qualquer tratamento; destes $85 \%$ são esgotos domésticos e $15 \%$ esgotos industriais. Em áreas urbanas a elevada densidade populacional produz alto volume de esgoto, e em cidades desprovidas de sistema de esgotamento sanitário eficiente, as águas subterrâneas podem ser contaminadas por meio da infiltração oriunda de fossas negras e pelo escoamento superficial da água da chuva em contato com o esgoto lançado a céu aberto.

Já os mananciais subterrâneos são recursos naturais utilizados tradicionalmente para abastecer grande parte da população brasileira em áreas rurais, e também nas cidades que não oferecem acesso à rede pública de abastecimento ou 0 abastecimento é irregular. Entretanto, 0 crescimento deste modo de utilização deste recurso foi acompanhado da proliferação de poços construídos, sem levar em conta critérios técnicos adequados que permitissem condições qualitativas básicas de potabilidade. Deste modo, a perfuração de poços com locação inadequada coloca em risco a qualidade das águas subterrâneas, uma vez que gera uma conexão entre as águas mais rasas, e, portanto, mais suscetíveis à contaminação, com águas mais profundas menos vulneráveis (ANA, 2007, p.95).

Por ser a água um bem de primeira necessidade, constituindo-se um recurso de uso comum, é utilizada, cotidianamente, para dessedentação humana e de animais, preparo de alimentos, higiene e asseio corporal, limpeza doméstica, descarga de vasos sanitários, entre outros usos importantes (SOTO et al., 2006, p.107). Assim, as cidades que possuem um sistema de tratamento e abastecimento de água potável eficiente, tendem a apresentar ambientes mais saudáveis para seus habitantes, colaborando com a manutenção de índices positivos de qualidade ambiental, diminuindo a incidência de doenças de veiculação hídrica, bem como contribuindo direta e indiretamente na melhoria da qualidade de vida dos seus habitantes.

Segundo Amaral (1996, p.108), os principais indicadores de contaminação fecal são as concentrações de coliformes totais e fecais, expressas em número de organismos por $100 \mathrm{~mL}$ de água. A presença deles na água não representa por si só um perigo à saúde, mas indica a possível presença de outros organismos causadores de problemas à saúde. Por exemplo, as bactérias do grupo coliforme, em especial a Escherichia coli, representa contaminação fecal recente e indica a 2005, p. 43). Todavia, a maioria das doenças de veiculação hídrica pode ser reduzida, controlada, desde que se possibilite o acesso à água potável. Entretanto, um dos maiores problemas das fontes 
A cidade de Anastácio, localizada a sudoeste do estado de Mato Grosso do Sul (MS), tem despertado preocupação quanto à qualidade das águas subterrâneas, considerando-se a influência de fatores sanitários e socioeconômicos domiciliares, por ser uma cidade com significativa carência de saneamento básico domiciliar, apresentando uma pequena rede de captação de esgoto sanitário, e prevalecendo o uso de fossas rudimentares na maioria dos domicílios da cidade, com $77,3 \%$, em 2002 (AYACH, 2002, p. 94) e de 52,2\% em 2009 (AYACH, 2011 p. 115), consideradas inadequadas, que interferem direta e indiretamente no comprometimento da qualidade do lençol freático, tanto por situações pontuais quanto difusas.

Assim, a cidade de Anastácio como na maioria das cidades pequenas a população capta água de poços rasos do tipo escavado e construídos sem critérios técnicos, localizados próximos de uma fossa e sem proteção como tampa, calçada ao redor, revestimento interno e cobertura externa entre outros fatores de proteção, que impedem a entrada da água da chuva diminuindo a possibilidade de contaminação química e microbiológica das águas.

Logo, objetivou-se estudar a qualidade das águas desses poços e a relação dessa qualidade com as condições de infraestrutura de construção, de proteção, manutenção e localização dos poços, nos diferentes setores da cidade de Anastácio (MS), tendo como indicador o Número Mais Provável (NMP) de coliformes totais e fecais (termotolerantes), e os parâmetros físico-químicos, cloreto, $\mathrm{pH}$, condutividade elétrica, dureza total e alcalinidade total.

\section{Materiais e Métodos}

Localização e caracterização da área de estudo

O município de Anastácio situa-se entre as latitudes $20^{\circ} 23^{\prime} 54^{\prime \prime} \mathrm{S}$ e $21^{\circ} 03^{\prime} 59^{\prime \prime} \mathrm{S}$, e as longitudes de $55^{\circ} 24^{\prime} 22^{\prime \prime}$ W e $56^{\circ} 19^{\prime} 57^{\prime \prime}$ W. Localiza-se na porção centro-sudoeste do estado de Mato Grosso do Sul, na microrregião geográfica de Aquidauana (MRG 002). Ocupa uma área urbana de $10,057 \mathrm{~km} 2$, entre as latitudes $20^{\circ} 28^{\prime} 12^{\prime \prime} \mathrm{S}$ e $20^{\circ} 30^{\prime} 08^{\prime \prime} \mathrm{S}$ e as longitudes $55^{\circ} 47^{\prime} 02^{\prime \prime} \mathrm{W}$ e $55^{\circ} 48^{\prime} 27^{\prime \prime}$ 'W; localizando-se a 143 quilômetros da capital do estado. O município de Aquidauana é seu limite a Leste, separado da área urbana de Anastácio pelo rio Aquidauana; a Oeste, ficam os municípios de Nioaque, Maracaju e Bonito; ao Norte, limita-se com Miranda e Bodoquena; ao Sul, com Dois Irmãos do Buriti.

Os dados referentes ao município de Anastácio registrados pela Contagem da População de 2007 (BRASIL, 2007), eram de 22.364 habitantes, sendo 11.251 homens e 11.007 mulheres. A população urbana apresentava 18.119 habitantes, e a população rural, 4.245 habitantes. A taxa de urbanização registrada em 2007 foi 81,02\%. , sendo a densidade demográfica do município de 7,84 hab/km2, e a densidade demográfica da área urbana 1.802 hab/km2 (AYACH, 2011 p. 55).

A cidade de Anastácio apresenta uma ocupação distribuída irregularmente, com áreas bastante adensadas e outras com vazios urbanos, observando-se que as subdivisões de alguns bairros da cidade não estão devidamente oficializadas. Assim, para determinação dos setores da cidade e distribuição dos poços a serem amostrados, optou-se em considerar a subdivisão conforme dados do Departamento de Controle de Vetores e Endemias da Secretaria Municipal de Saúde e Saneamento de Anastácio, os quais são constantemente atualizados, correspondendo a cinco grandes setores: Centro, Vila Rodrigues, Vila Flor, Vila Umbelina e Jardim Independência (Tabela 1).

Geografia Ensino \& Pesquisa, v. 16, n.3 p. $77-92$, set./dez. 2012

Cappi, N.; Ayach, N. R.; Santos, T. M. B.; Guimarães, S. T. L. 
Tabela 1 - Dados populacionais dos Setores da Cidade de Anastácio-MS.

\begin{tabular}{|c|c|c|c|c|c|c|}
\hline SETORES & Domicilio & $\begin{array}{c}\text { P o p u la çã o } \\
\text { Estimada }\end{array}$ & \multicolumn{2}{|c|}{ Área Total (ha) } & \multicolumn{2}{|c|}{ Densidade Dem. (hab km-2) } \\
\hline Centro & 980 & 3.136 & 126 & 309,10 & - & - \\
\hline Rodrigues & 826 & 1.982 & 154 & 299,50 & - & - \\
\hline Flor & 1.730 & 6.228 & 344 & 82,60 & 94,2 & 5,8 \\
\hline Umbelina & 1.343 & 4.566 & 292 & 184,40 & 85,5 & 14,5 \\
\hline Independência & 284 & 1.250 & 25 & 377,20 & 75,6 & 24,4 \\
\hline Total & 5.163 & 17.162 & 940 & 250,56 & - & - \\
\hline
\end{tabular}

Fonte: Ayach (2011).

O clima da região da cidade de Anastácio é caracterizado por grande irregularidade nas cotas pluviométricas. 0 período chuvoso prolonga-se por seis meses, de outubro a março, apresentando maior concentração em dezembro e janeiro, e uma estação mais seca de abril a setembro (Figura 1).

Figura 1 - Precipitação e temperatura média mensal do município de Anastácio nos anos de 2008 e 2009.

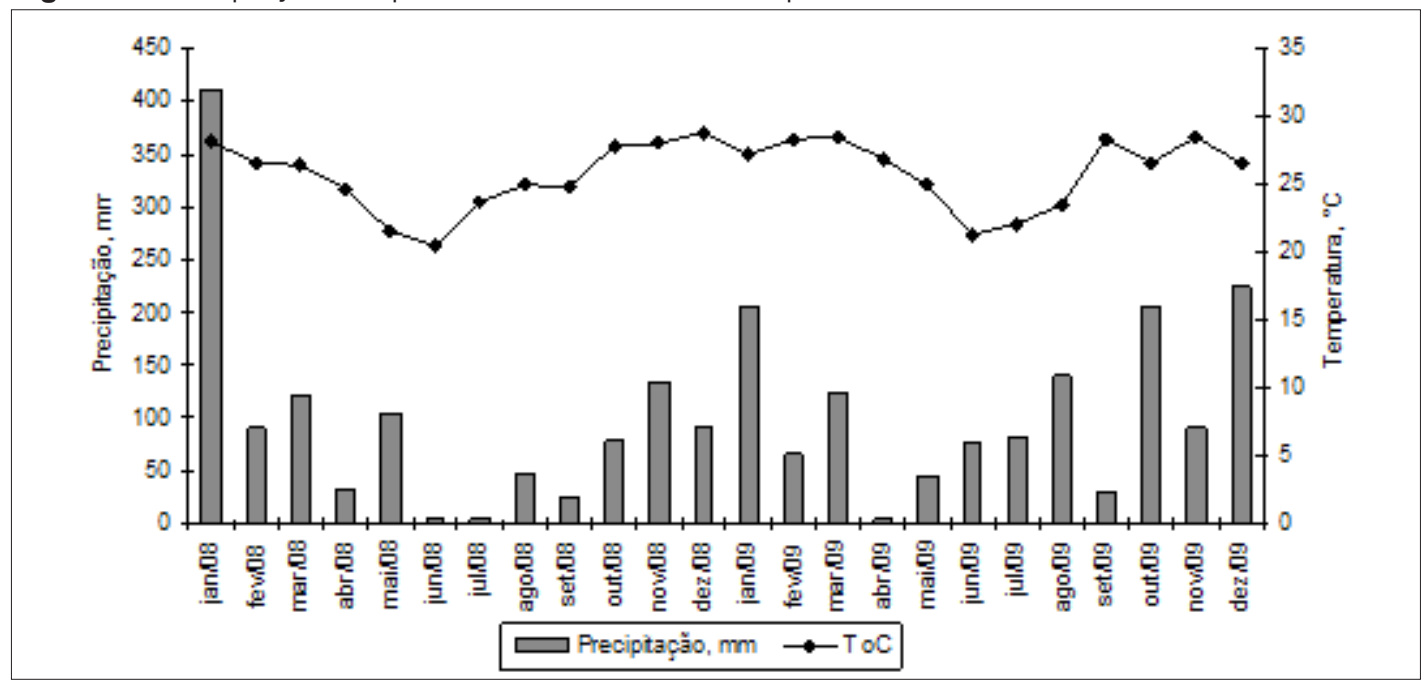

Fonte: Estação Climatológica Automática de Aquidauana (MS).

A média térmica da região registra em torno de $25^{\circ} \mathrm{C}$, ao passo que a média do mês mais quente (janeiro) pode alcançar $27,5^{\circ} \mathrm{C}$, e a do mês mais frio (julho) atinge $22,5^{\circ} \mathrm{C}$, porém, é comum na região temperaturas superior a $40^{\circ} \mathrm{C}$ nos meses de verão e inferiores a $5^{\circ} \mathrm{C}$ nos meses de inverno.

De acordo com Leal (1999), a área onde está situado o município de Anastácio localiza-se no domínio do aquífero da Bacia Sedimentar do Paraná (Brasil) também conhecido como Aquífero Guarani, com 1.000.000 de km2, que abrange além da Formação Aquidauana, sobre a qual se localiza a cidade de Anastácio, as formações Bauru-Caiuá, Serra Geral, Botucatu-Pirambóia-Rio do Rastro, como sistemas aquíferos principais, com volumes estocados de $50.400 \mathrm{~km} 3$.

Pinto (1998), utilizando-se da geofísica, através de sensor eletromagnético EM 31 e EM 39, observou que a inclinação das camadas de deposição da Formação Aquidauana em profundidades

Geografia Ensino \& Pesquisa, v. 16, n. 3 p. $77-92$, set./dez. 2012

Qualidade da água e fatores de contaminação de poços rasos na área urbana de Anastácio(MS) de 3 a 30 metros, onde fluem as águas freáticas, é a mesma da superfície. E que, devido às características hidrogeológicas e hidrogeomorfológicas, constituem um "efeito esponja" que propicia um grande armazenamento de água em nível freático, porém extremamente suscetível à contaminação. O subaquífero Aquidauana é resultante desse sistema poroso em rochas sedimentares areníticas que propicia elevada infiltração e grande disponibilidade hídrica.

Contudo, esses terrenos apesar de possuírem grande potencial hídrico constituem ambientes de fragilidade, devido a processos de contaminação, consideradas as vulnerabilidades ambientais da área. 
Para a análise da qualidade das águas dos poços da cidade de Anastácio, foram realizadas quatro coletas sazonais; no inverno/2008, verão/2008, inverno/2009 e verão/2009 em doze poços (Figura 2), selecionados nos setores da cidade; setor-01: Centro (P4 e P12); setor- 02: Vila Rodrigues (P10 e P11); setor 03: Vila Flor (P6, P7, P8 e P9); setor 04: Vila Umbelina (P1, P2, P3 e P5).

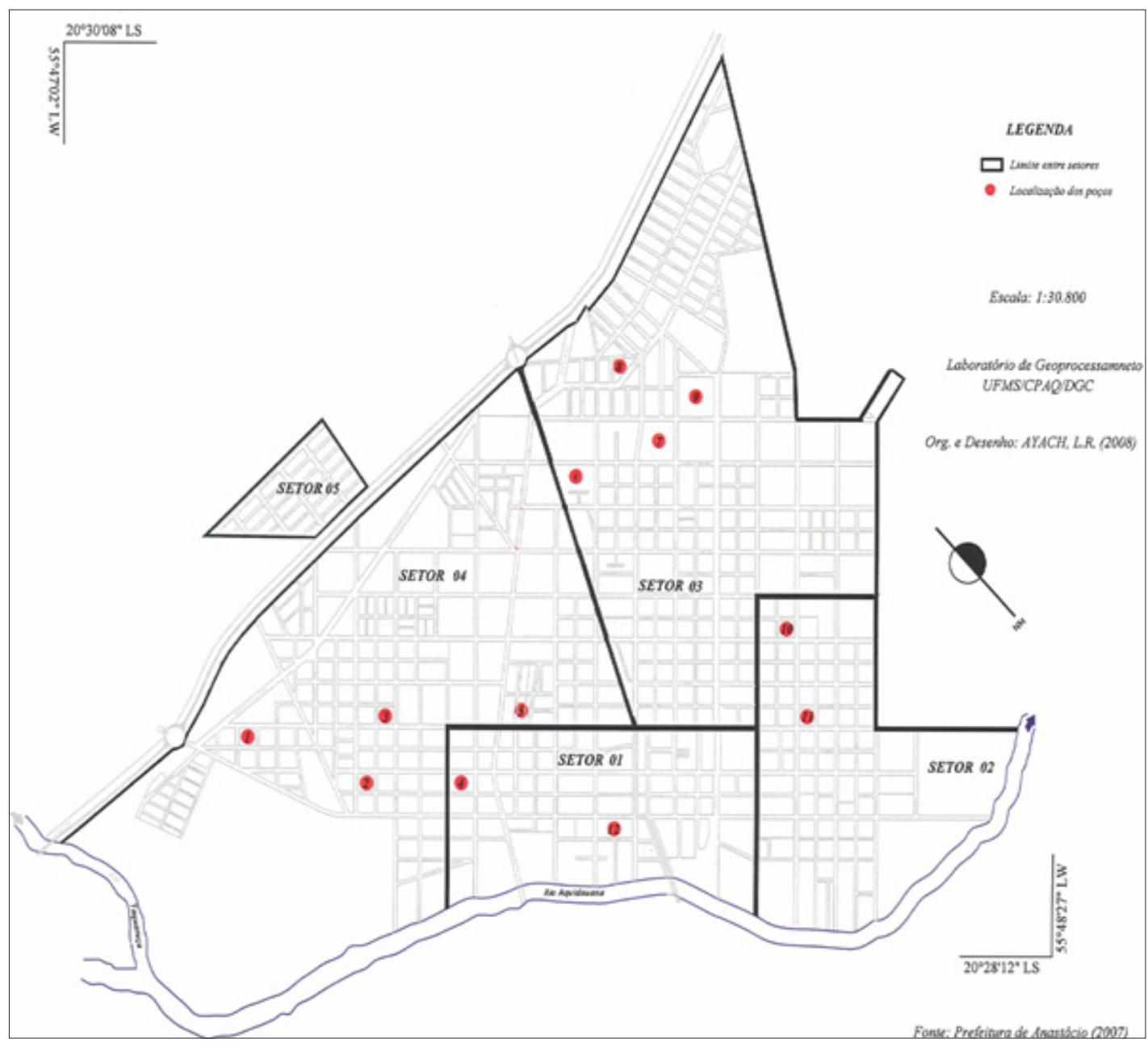

Figura 2 - Localização dos poços analisados na área urbana de Anastácio.

Fonte: Prefeitura de Anastácio.

Os poços foram selecionados mediante estudo realizado por Ayach (2002, p. 22) e Ayach (2011 p.83), são considerados representativos dentro dos respectivos setores de acordo com a sua localização, características e pela confirmação de que os mesmos se encontravam em uso pelo morador. Portanto, como no setor 05 - Jardim Independência, localizado após a BR 262, não havia nenhum poço em utilização, este setor não foi monitorado. No entanto, os setores com maior prevalência de interrupção no abastecimento da rede ou sem atendimento da rede de abastecimento, consequentemente, tinham mais poços em utilização, ocasionando maior número de poços amostrados, como os setores Vila Umbelina e Vila Flor.

As informações sobre as características dos poços selecionados tais como: profundidade, localização, tipo de captação de água e suas condições sanitárias, foram coletadas por meio de um questionário informativo de campo. 0 método de coleta consistiu na captação das amostras de águas dos poços escavados por meio de amostradores adequados para cada tipo de análise.

As amostras destinadas às análises de cloreto, alcalinidade total e dureza total foram coletadas em frascos de polietileno, e analisadas no mesmo dia. A alcalinidade total e a dureza

Geografia Ensino \& Pesquisa, v. 16, n.3 p. $77-92$, set./dez. 2012

Cappi, N.; Ayach, N. R.; Santos, T. M. B.; Guimarães, S. T. L. 
total pelo método titulométrico (APHA, AWWA, WPCF, 1995) e cloreto por Mohr-titulométrico. O $\mathrm{pH}$ e a Condutividade elétrica (CE) pelo método eletrométrico, foram analisados em loco com os equipamentos: peagâmetro (PHTEK-pH100) e Condutivímetro (PHTEK-CD203).

As amostras para a análise de coliformes totais e fecais foram coletadas em frascos de vidro de $250 \mathrm{~mL}$, esterilizados em autoclave a $121^{\circ} \mathrm{C}$, durante 30 minutos. Após a coleta, as amostras foram acondicionadas em caixa térmica e transportadas para o laboratório, sendo analisadas no mesmo dia. As análises seguiram a técnica dos Tubos Múltiplos e os resultados expressos em Número Mais Provável de Coliformes Totais e Fecais (NMP100 mL-1), com base na metodologia descrita por APHA, AWWA, WPCF (1995). No laboratório, após a agitação dos frascos com as amostras, com o auxílio de um pipetador automático com ponteira esterilizada, foi retirado $1 \mathrm{~mL}$ da amostra de água e transferido para um tubo contendo $9 \mathrm{~mL}$ de água peptonada $(0,1 \%)$.

Em seguida, homogeneizou-se o conteúdo por agitação e com outra ponteira estéril transferiuse $1 \mathrm{~mL}$ da diluição $10^{-1}$ para a diluição $10^{-2}$ e assim para a $10^{-3}$. Depois de realizadas as diluições e homogeneizadas, para o teste presuntivo foi colocado $1 \mathrm{~mL}$ de cada diluição em tubos contendo caldo lauril triptose, com tubos de Durham invertidos em seu interior. As amostras foram incubadas a $35+0,5^{\circ} \mathrm{C}$ por $48 \mathrm{~h}$. Foram considerados testes positivos aqueles que apresentaram formação de gás dentro dos tubos de Durham e turbidez do meio. Com esses resultados, foi realizada a prova confirmativa para coliformes totais, utilizando caldo lactose bile verde brilhante, e para coliformes fecais (termotolerantes) o caldo EC, com tubos de Durham invertidos.

A inoculação foi realizada por meio da transferência de uma gota retirada dos tubos positivos, com o auxílio de uma alça de platina. As amostras foram incubadas a $35^{\circ} \mathrm{C}$ durante $48 \mathrm{~h}$ para coliformes totais e em banho-maria a $44,5^{\circ} \mathrm{C}$ para coliformes fecais. Foram consideradas positivas as amostras que apresentaram gás dentro do tubo de Durham e os resultados foram expressos em valores de Número Mais Provável por $100 \mathrm{~mL}$ de amostra (NMP100 $\mathrm{mL}^{-1}$ ).

As informações de precipitação pluviométrica e temperatura foram coletadas na Estação Climatológica Automática de Aquidauana.

\section{Resultados e discusões}

Características dos poços analisados na área urbana de Anastácio

Com relação à forma de abastecimento de água domiciliar, dos 12 poços monitorados, em $41,66 \%$ das residências essa era a única forma de abastecimento de água, e em 58,33\% o abastecimento também era feito pela rede pública (Tabela 2).

As condições das edificações, higiênico-sanitárias e a localização dos poços constituem fatores importantes que estão diretamente ligados à saúde das pessoas que consomem a água, especialmente em relação às crianças que são mais vulneráveis às doenças de veiculação hídrica.

Tabela 2 - Características dos poços selecionados na área urbana de Anastácio (MS), 2008 e 2009.

Geografia Ensino \& Pesquisa, v. 16, n.3 p. $77-92$, set./dez. 2012

Qualidade da água e fatores de contaminação de poços rasos na área urbana de Anastácio(MS)

\begin{tabular}{|c|c|c|}
\hline \multicolumn{2}{|c|}{ Características } & Porcentagem (\%) \\
\hline \multirow{2}{*}{ Abastecimento domiciliar } & Poço & 41,66 \\
\cline { 2 - 3 } & Poço e rede pública & 58,33 \\
\hline \multirow{2}{*}{ Tipo de perfuração do poço } & Escavado & 100 \\
\cline { 2 - 3 } & Tubular & - \\
\hline
\end{tabular}




\begin{tabular}{|c|c|c|}
\hline Formas de captação de água & Bombeamento & 66,7 \\
\cline { 2 - 3 } & Manual com balde & 33,3 \\
\hline \multirow{3}{*}{ Profundidade do poço $(\mathrm{m})$} & até 5 & 25 \\
\cline { 2 - 3 } & 6 a 10 m & 33,3 \\
\cline { 2 - 3 } & 11 a 15 m & 41,7 \\
\hline
\end{tabular}

Fonte: Ayach (2011).

Os poços analisados foram do tipo escavado, forma de construção mais difundida para captação de água do lençol freático na periferia das cidades e em áreas rurais. São construídos por meio de uma escavação manual do solo, com um diâmetro de aproximadamente um metro e recebe a denominação técnica de poço raso ou poço freático.

Em $66,7 \%$, a forma de captação de água dos poços era por bombeamento, e em $33,3 \%$ manual com balde, destacando-se que neste procedimento pode ocorrer contaminação da água pela inadequação das condições de higiene do coletor, que normalmente é um balde que fica exposto e não é higienizado antes de ser usado.

Dos doze poços estudados 25\% são do tipo raso com até $5 \mathrm{~m}, 33,3 \%$ entre 6 a $10 \mathrm{~m}$ e 41,7\% de 11 a $15 \mathrm{~m}$. A profundidade dos poços é uma das características que podem estar relacionada à qualidade da água. Entende-se que a profundidade pode reduzir a possibilidade de contaminação por substâncias que possuem baixa mobilidade no solo. Aárea urbana de Anastácio assenta-se sobre um raso pacote de materiais inconsolidados irregularmente distribuído, provenientes das formações Aquidauana e Botucatu, que favorecem a perfuração de poços rasos (58,3\% até $10 \mathrm{~m}$ de profundidade) e, consequentemente, a contaminação das águas por fossas, deposição inadequada de lixo e de água servida a céu aberto.

Na cidade de Anastácio a carência de abastecimento público de água potável torna a perfuração de poços uma prática frequente, sobretudo, nos bairros da periferia. Esses poços não apresentam proteção adequada, capaz de evitar a contaminação externa de suas águas. A parede externa acima do solo que é um fator importante na proteção dos poços foi encontrada em $41,7 \%$ dos poços com até $25 \mathrm{~cm}, 25 \%$ de 26 até $50 \mathrm{~cm}$ e em $33,3 \%$ com mais de $50 \mathrm{~cm}$. Os poços com tampa e calçamento no entorno somaram $58,3 \%$ (Figuras 3 e 4 ;Tabela 3).

A predominância de fossas rudimentares ou negras, localizadas próximas dos poços com $16,7 \%$ a menos de $10 \mathrm{~m}$ de distância e $41,7 \%$ de 10 a $20 \mathrm{~m}$, aliada a reduzida espessura do material inconsolidado presente na área da cidade, facilita a ligação dessas fossas com as águas freáticas (AYACH, 2002, p.94), tornando a área urbana um local susceptível a contaminação das águas do lençol freático que abastece os poços rasos.

Figura 3 - Poço monitorado n 10, sem proteção.

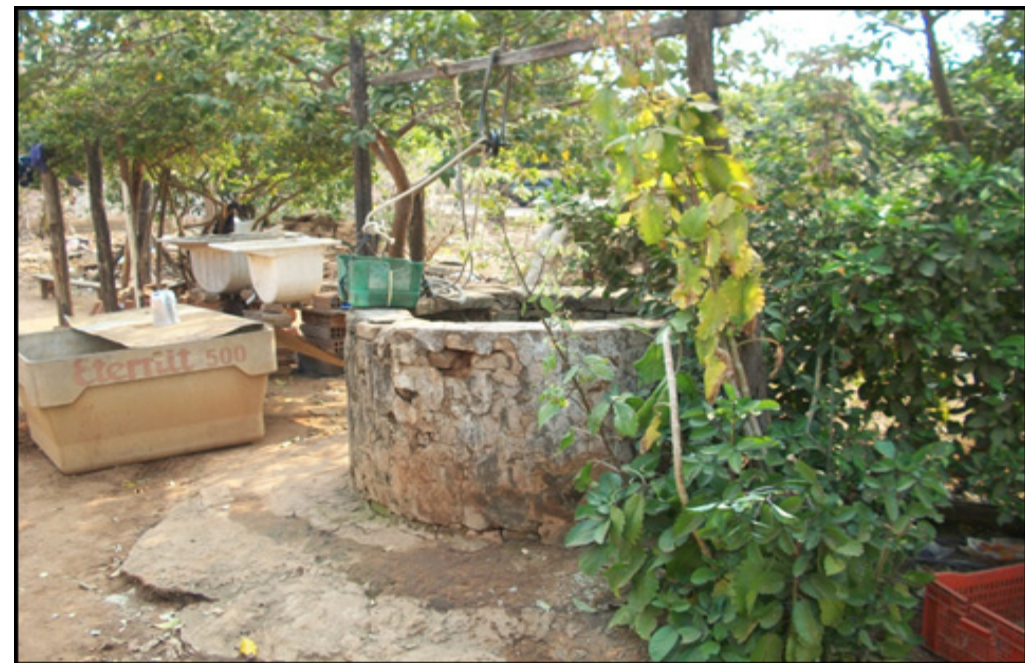

Geografia Ensino \& Pesquisa, v. 16, n.3 p. $77-92$, set./dez. 2012

Cappi, N.; Ayach, N. R.; Santos, T. M. B.; Guimarães, S. T. L.

ISSN 2236-4994 
Figura 4 - Poço monitorado n 06, com precária proteção e condições do entorno.

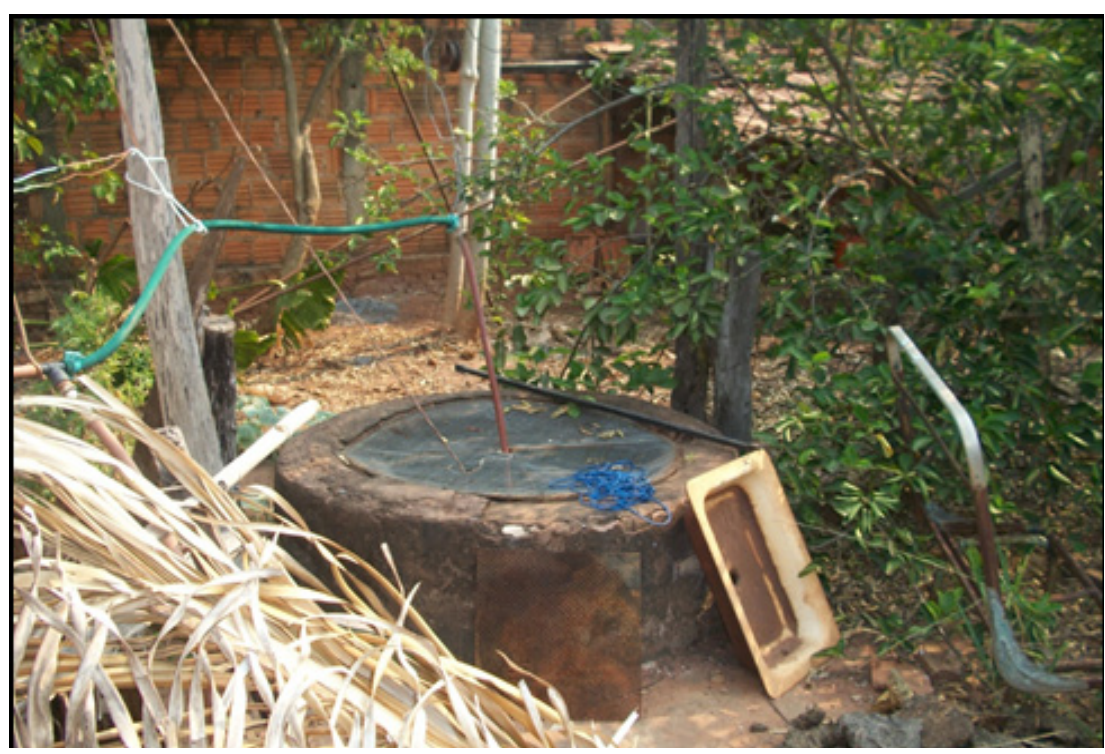

Fonte: Ayach, L.R, agosto/2010.

Em 91,7\% dos poços, observou-se a existência de cobertura, que além de proteger a estrutura externa evitando que a água da chuva carregue a sujeira para dentro do poço, impede também a entrada do escoamento superficial que pode, em muitos casos, provocar o desmoronamento das paredes em poços que não possuem revestimento interno.

Tabela 3- Fatores de proteção dos poços selecionados na área urbana de Anastácio-MS, 2008 e 2009

\begin{tabular}{|c|c|c|}
\hline \multicolumn{2}{|c|}{ Fatores de proteção } & \multirow{2}{*}{$\begin{array}{c}\text { Porcentagem (\%) } \\
41,7\end{array}$} \\
\hline \multirow{3}{*}{$\begin{array}{l}\text { Parede externa acima do solo } \\
\qquad(\mathrm{cm})\end{array}$} & 0 a 25 & \\
\hline & 26 a 50 & 25 \\
\hline & $>50$ & 33,3 \\
\hline \multirow[t]{2}{*}{ Tampa } & Sim & 58,3 \\
\hline & Não & 41,7 \\
\hline \multirow[t]{2}{*}{ Calçada ao redor do poço } & Sim & 58,3 \\
\hline & Não & 41,7 \\
\hline \multirow{3}{*}{$\begin{array}{c}\text { Distância do poço a fossa mais } \\
\text { próxima (m) }\end{array}$} & $<10$ & 16,7 \\
\hline & 10 a 20 & 41,7 \\
\hline & $>20$ & 16,7 \\
\hline \multirow[t]{2}{*}{ Revestimento interno } & Sim & 91,7 \\
\hline & Não & 8,3 \\
\hline \multirow[t]{2}{*}{ Cobertura externa } & Sim & 50 \\
\hline & Não & 50 \\
\hline
\end{tabular}

Geografia Ensino \& Pesquisa, v. 16, n. 3 p. $77-92$, set./dez. 2012

Qualidade da água e fatores de contaminação de poços rasos na área urbana de Anastácio(MS)
Fonte: Adaptado de Ayach (2011).

A opinião de 58,3\% dos consumidores (Tabela 4) de que a água possuía ótima qualidade, demonstrou que se a água do poço estiver aparentemente limpa e sem sabor já é suficiente para ser considerada de boa qualidade. 0 fato de a água subterrânea ser considerada, na maioria das vezes de boa qualidade, impede que os consumidores tratem essa água, pelo menos por um processo de desinfecção, o que certamente minimizaria o risco de veiculação de enfermidades. (AMARAL et al., 
2003, p.512). Diante deste cenário, devem-se considerar ainda os níveis da percepção ambiental da população, mais a influência dos filtros perceptivos dos moradores, não apenas em relação ao poço $\mathrm{e}$ uso da água, mas, sobretudo, em relação às condições da utilização dos recursos naturais em geral, bem como da qualidade ambiental, no que tange à proteção do meio ambiente e preservação das condições adequadas de potabilidade. A identificação da percepção e das formas de interpretação da realidade vivenciada no cotidiano vem se tornando aspectos muito relevantes nos processos de gestão ambiental participativa, em especial quando pertinentes à gestão dos recursos hídricos, elaboração de políticas públicas, seleção de diretrizes de planejamento, implantação de programas, etc.

Tabela 4 - Opinião dos consumidores sobre a qualidade da água dos poços selecionados na área urbana de Anastácio-MS em 2008 e 2009.

\begin{tabular}{|c|c|}
\hline Descrição & Porcentagem (\%) \\
\hline Ótima & 58,3 \\
\hline Boa & 16,8 \\
\hline Boa e leve & 8,3 \\
\hline Salobra & 8,3 \\
\hline Não é boa & 8,3 \\
\hline
\end{tabular}

Fonte: pesquisa de campo amostral (2009)

Segundo Ayach et al. (2009, p. 21), mesmo nos domicílios que são abastecidos pela rede pública, por questões econômicas e culturais, é comum a utilização de água de poço. Estes recebem, no máximo, uma desinfecção esporádica com cloro pelos agentes de saúde municipal, não existindo por parte do poder público, de qualquer tipo de orientação por meio de campanhas ou programas educativos, relacionados aos cuidados que devem ser tomados com os poços e com relação à deposição de lixo e esgoto doméstico no entorno.

Qualidade das águas dos poços na área urbana de Anastácio

Todas as amostras analisadas apresentaram bactérias do grupo coliformes (Tabela 5). Visto que, mesmo as amostras que apresentaram menos de 30 bactérias por $100 \mathrm{~mL}$ não significam ausência de contaminação, apenas que o número de bactérias encontrado não atingiu a sensibilidade do método, portanto, a possibilidade de contaminação existe.

Das amostras coletadas nos poços do setor Vila Umbelina, 56,3\% apresentaram mais de 30 bactérias por $100 \mathrm{~mL}$, no setor Vila Flor 46,9\%, na Vila Rodrigues $81,03 \%$ e $56,3 \%$ no Centro. Os valores máximos e as médias foram superiores no inverno em todos os setores com exceção da Vila Rodrigues, com valor superior no verão. Os mínimos, com menos de 30 bactérias, foram observados em todos os setores, tanto nos períodos seco (inverno), como no chuvoso (verão).

Tabela 5 - Máximos, mínimos, médias e porcentagens de amostras com valores superior a 30 NMP 100 $\mathrm{mL}^{-1}$ encontrados nas águas dos poços nos setores da cidade de Anastácio-MS em 2008 e 2009.

\begin{tabular}{|c|c|c|c|c|c|c|c|}
\hline \multirow{2}{*}{ Setores } & \multicolumn{3}{|c|}{ Verão } & \multicolumn{3}{c|}{ Inverno } & \multirow{2}{*}{$\%$} \\
\cline { 2 - 8 } & Máximo & Mínimo & Média & Máximo & Mínimo & Média & \\
\hline Vila Umbelina & 930 & $>30$ & 170,6 & 2400 & $>30$ & 305,6 & 56,3 \\
\hline Vila Flor & 2400 & $>30$ & 204,4 & 4600 & $>30$ & 441,9 & 46,9 \\
\hline Vila Rodrigues & 11000 & $>30$ & 2201 & 4600 & $>30$ & 955 & 81,3 \\
\hline Centro & 2400 & $>30$ & 381 & 11000 & $>30$ & 2166 & 56,3 \\
\hline
\end{tabular}

Fonte: pesquisa de campo (2009)

Geografia Ensino \& Pesquisa, v. 16, n.3 p. 77 -92, set./dez. 2012

Cappi, N.; Ayach, N. R.; Santos, T. M. B.; Guimarães, S. T. L. 
A Portaria 518 MS (BRASIL, 2004) no Art. 11, estabelece que em amostras individuais de água de poço sem distribuição canalizada, tolera-se a presença de coliformes totais, na ausência de coliformes termotolerantes, devendo ser investigadas e tomadas as providências de caráter corretivo e preventivo. Considerando que as águas desses poços são consumidas sem nenhum tipo de tratamento prévio, a presença de bactérias em todas as amostras torna a água imprópria para 0 consumo humano.

Silva e Araujo (2003, p.1024) analisaram 120 amostras de água subterrânea e constataram que o crescimento de coliformes termotolerantes estava associado a poços rasos com até $10 \mathrm{~m}$ de profundidade. Logo, esperava-se que os valores de coliformes sofressem influência da profundidade dos poços (Figura 5), relação observada somente nos poços 4 (Centro); 10 e 11 (Vila Rodrigues), todos com menos de $10 \mathrm{~m}$ de profundidade e valores elevados de coliformes totais e fecais. Nos demais não foram constatados uma relação aparente entre essas duas variáveis, mesmo porque todos os poços possuem profundidade inferior a $15 \mathrm{~m}$.

Figura 5 - Profundidade dos poços e valores médios do NMP100 $\mathrm{mL}^{-1}$ de coliformes totais no verão (A) e inverno (B) e de coliformes fecais no verão (C) e no inverno (D).

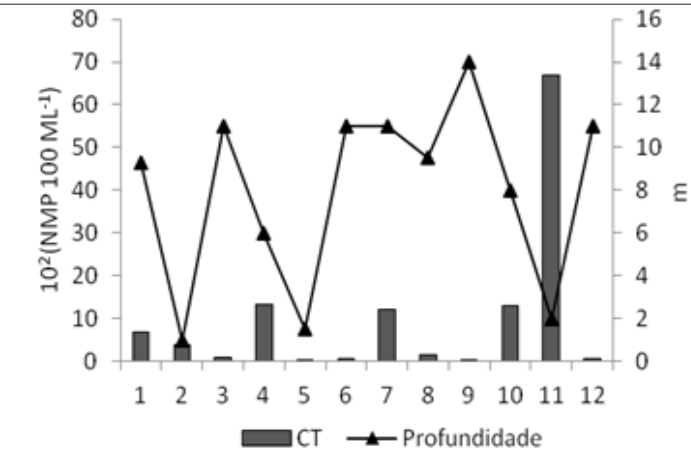

A

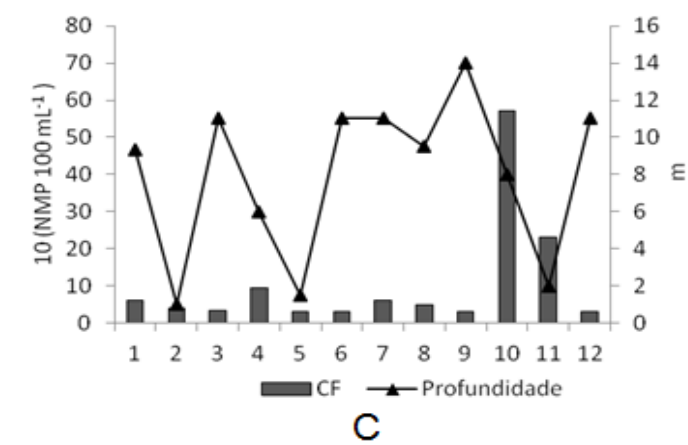

Fonte: pesquisa de campo (2009)

A sazonalidade também não teve influência direta nas concentrações de coliformes, sendo que os poços 4, 7, 10 e 11 apresentaram concentrações elevadas para CT no verão (Figura $5 \mathrm{~A}$ ), com exceção dos poços 4 e 8 e 10 que as concentrações no inverno foram maiores (Figura 5B), para CF (Figuras 5C e 5D) o poço 4 também apresentou maior concentração no inverno.

Observou-se que todos os setores da cidade apresentaram poços contaminados por coliformes, incluindo o setor centro que possui melhor adequação de infraestrutura de saneamento básico, com uma maior cobertura do serviço de rede de captação de esgoto sanitário público. Logo, fatores higiênico-sanitários referentes à construção e manutenção dos poços podem ser determinantes para qualidade das águas.

De acordo com Figura 6, observa-se que as estações com valores mais elevados do NMP100 mL-1 de bactérias foram o verão/08 e o inverno/09, portanto a sazonalidade não apresentou efeito regular entre as estações secas e chuvosas. Esses resultados podem ter sofrido a influência das chuvas irregulares no período das coletas (Figura 1), como o inverno com precipitações acima da média da região, não definido 
como verão chuvoso e inverno seco, contrariando os resultados encontrados por Nogueira et al., (2003, p.232) constatou altas porcentagens de amostras contaminadas, na região de Maringá, estado do Paraná (PR), no período quente e uma redução no período frio com o decréscimo da temperatura da água. Cappi, Carvalho e Pinto (2006, p. 44) observaram em áreas rurais, elevadas concentrações de bactérias do grupo coliformes em água de poços rasos no verão, e reduzidas no inverno.

Figura 6 - Valores de coliformes totais e fecais nas estações analisadas

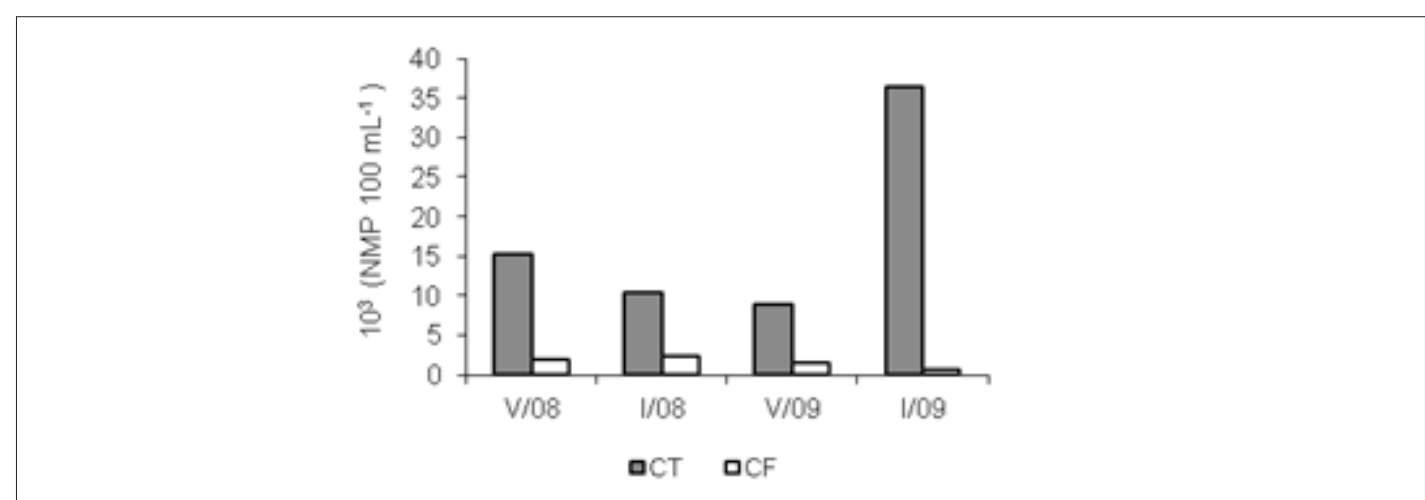

Fonte: pesquisa de campo (2009)

Também se verificou que as concentrações de alcalinidade total foram reduzidas em todos os poços (Tabela 6), com a ocorrência de valores mais elevados nos poços 9 (Vila Flor) 4 e 12 (Centro). Os valores elevados de alcalinidade nas águas expressam a capacidade de tamponamento que impede mudanças bruscas no $\mathrm{pH}$. Os aumentos de seus valores nas águas subterrâneas e fluviais são em virtude dos processos de intemperismo químico (CONCEIÇÃO et al., 2009 p.72).

Tabela 6 - Valores máximos, mínimos e médias das variáveis encontradas nas águas dos poços.

\begin{tabular}{|c|c|c|c|c|c|c|c|}
\hline \multirow{3}{*}{ Parâmetros } & \multirow{3}{*}{ Valores } & \multicolumn{6}{|c|}{ Setores/poços } \\
\hline & & \multicolumn{3}{|c|}{ Vila Umbelina } & \multicolumn{3}{|c|}{ Vila Rodrigues } \\
\hline & & P1 & P2 & P3 & P5 & P10 & P11 \\
\hline \multirow{3}{*}{$\begin{array}{l}\text { Alcalinidade } \\
\quad\left(\mathrm{mgL}^{-1}\right)\end{array}$} & Máximo & 20,7 & 31,8 & 16,6 & 18,6 & 20,1 & 26,9 \\
\hline & Mínimo & 0,0 & 21,7 & 0,0 & 9,1 & 10,4 & 5,2 \\
\hline & Média & 8,0 & 26,8 & 4,1 & 14,2 & 16,3 & 14,6 \\
\hline \multirow{3}{*}{$\begin{array}{l}\text { Dureza } \\
\left(\mathrm{mgL}^{-1}\right)\end{array}$} & Máximo & 90,1 & 66,0 & 103,1 & 50,0 & 297,0 & 148,1 \\
\hline & Mínimo & 20,0 & 47,0 & 53,1 & 26,0 & 106,6 & 128,1 \\
\hline & Média & 56,3 & 57,8 & 73,8 & 41,9 & 169,5 & 140,1 \\
\hline \multirow{3}{*}{$\begin{array}{l}\text { Cloreto } \\
\left(\mathrm{mgL}^{-1}\right)\end{array}$} & Máximo & 283,6 & 153,8 & 336,5 & 173,1 & 320,1 & 418,2 \\
\hline & Mínimo & 151,4 & 117,8 & 163,4 & 158,6 & 158,6 & 178,0 \\
\hline & Média & 201,9 & 135,8 & 217,5 & 165,8 & 246,5 & 248,8 \\
\hline \multirow{3}{*}{$\mathrm{pH}$} & Máximo & 5,4 & 6 & 4,6 & 5,8 & 5,9 & 5,1 \\
\hline & Mínimo & 3,5 & 5 & 3,6 & 5,2 & 4,8 & 4,7 \\
\hline & Média & 4,3 & 5,6 & 4,2 & 5,5 & 5,1 & 4,9 \\
\hline \multirow{5}{*}{$\begin{array}{c}\text { CE } \\
\left(\mu \mathrm{Scm}^{-1}\right)\end{array}$} & Máximo & 673,6 & 197,0 & 667,1 & 438,0 & 2851,2 & 708,5 \\
\hline & Mínimo & 416,7 & 188,9 & 551,2 & 268,9 & 605,0 & 567,6 \\
\hline & Média & 509,3 & 190,9 & 630,7 & 328,5 & 1257,2 & 627,5 \\
\hline & & \multicolumn{3}{|c|}{ Vila Flor } & \multicolumn{3}{|c|}{ Centro } \\
\hline & & P6 & P7 & P8 & P9 & P4 & P12 \\
\hline
\end{tabular}

Geografia Ensino \& Pesquisa, v. 16, n.3 p. $77-92$, set./dez. 2012 


\begin{tabular}{|c|c|c|c|c|c|c|c|}
\hline \multirow{2}{*}{$\begin{array}{c}\text { Alcalinidade } \\
\left(\mathrm{mgL}^{-1}\right)\end{array}$} & Máximo & 16,6 & 12,4 & 20,1 & 64,2 & 95,3 & 182,2 \\
\cline { 2 - 8 } & Mínimo & 8,1 & 5,5 & 12,0 & 45,5 & 60,0 & 128,1 \\
\cline { 2 - 8 } & Média & $\mathbf{1 0 , 8}$ & $\mathbf{8 , 8}$ & $\mathbf{1 5 , 6}$ & $\mathbf{5 5 , 5}$ & $\mathbf{7 9 , 6}$ & $\mathbf{1 5 4 , 2}$ \\
\hline \multirow{2}{*}{$\begin{array}{c}\text { Dureza } \\
\left(\mathrm{mgL}^{-1}\right)\end{array}$} & Máximo & 120,0 & 40,0 & 20,0 & 74,1 & 79,1 & 175,2 \\
\cline { 2 - 8 } & Mínimo & 22,0 & 15,0 & 13,0 & 30,0 & 13,1 & 120,5 \\
\cline { 2 - 8 } & Média & $\mathbf{7 0 , 6}$ & $\mathbf{2 4 , 0}$ & $\mathbf{1 6 , 0}$ & $\mathbf{5 5 , 1}$ & $\mathbf{5 6 , 3}$ & $\mathbf{1 4 3 , 3}$ \\
\hline \multirow{2}{*}{$\begin{array}{c}\text { Cloreto } \\
\left(\mathrm{mgL}^{-1}\right)\end{array}$} & Máximo & 1038,3 & 168,3 & 201,9 & 177,9 & 278,8 & 182,7 \\
\cline { 2 - 8 } & Mínimo & 721,1 & 105,8 & 168,3 & 125,0 & 163,4 & 144,2 \\
\cline { 2 - 8 } & Média & $\mathbf{7 3 8 , 5}$ & $\mathbf{1 3 6 , 4}$ & $\mathbf{1 8 0 , 3}$ & $\mathbf{1 5 8 , 6}$ & $\mathbf{2 2 1 , 1}$ & $\mathbf{1 5 0 , 2}$ \\
\hline \multirow{2}{*}{$\mathrm{pH}$} & Máximo & 5,3 & 5,6 & 6,2 & 6,6 & 6,9 & 7,9 \\
\cline { 2 - 8 } & Mínimo & 4,0 & 4,8 & 5,2 & 5,6 & 5,4 & 6,9 \\
\cline { 2 - 8 } & Média & $\mathbf{4 , 9}$ & $\mathbf{5 , 2}$ & $\mathbf{5 , 8}$ & $\mathbf{6 , 2}$ & $\mathbf{6 , 3}$ & $\mathbf{7 , 4}$ \\
\hline \multirow{2}{*}{$\begin{array}{c}\mathrm{CE} \\
\left(\mu \mathrm{Scm}^{-1}\right)\end{array}$} & Máximo & 3838,0 & 194,4 & 399,0 & 332,0 & 674,2 & 835,0 \\
\cline { 2 - 8 } & Mínimo & 2633,6 & 100,1 & 158,5 & 125,8 & 380,2 & 530,0 \\
\cline { 2 - 8 } & Média & $\mathbf{3 3 1 3 , 9}$ & $\mathbf{1 6 5 , 1}$ & $\mathbf{2 8 0 , 3}$ & $\mathbf{2 4 3 , 4}$ & $\mathbf{5 2 1 , 5}$ & $\mathbf{6 7 0 , 4}$ \\
\hline
\end{tabular}

Fonte: pesquisa de campo (2009)

A dureza total a exemplo da alcalinidade também apresentou valores reduzidos em todas as coletas. Os valores elevados foram registrados nos poços 10 e 11 (Vila Rodrigues) e 12 (Centro). Os valores em todas as coletas não ultrapassaram o VMP de $500 \mathrm{mgL}^{-1}$.(BRASIL, 2004). As concentrações de dureza total em média nos poços 10, 11 e 12 em todas as amostras, ultrapassaram 100 mgL-1, logo, podem ser consideradas como água moderadamente dura, e nos demais poços como água mole. Como a dureza total apresentou valores superiores aos da alcalinidade total, entende-se que a concentração de dureza pode ser uma mistura entre dureza temporária e dureza permanente. A dureza total é expressa pela concentração total de íons alcalino-terrosos $\left(\mathrm{Ca}^{+2} \mathrm{e} \mathrm{Mg}^{+2}\right)$ presentes na água. Enquanto a dureza temporária é a fração da dureza total causada pela presença de bicarbonato de cálcio $\left(\mathrm{Ca}\left(\mathrm{HCO}_{3}\right)_{2(\mathrm{aq})}\right)$ e pode ser removida por aquecimento já a dureza permanente é resultante da presença de outros sais (principalmente os sais de sulfatos dissolvidos) que não podem ser removidos por aquecimento (HARRIS, 2005 p 269).

As concentrações de cloretos foram elevadas com valores mínimos acima de $100 \mathrm{mgL}^{-1}$, e máximos superiores ao VMP de $250 \mathrm{mgL}^{-1}$ para consumo humano (BRASIL, 2004), nos poços 1 e 3 (Vila Umbelina), 4 (Centro), 6 (Vila Flor), 10 e 11(Vila Rodrigues). 0 cloro é um elemento que aparece em pequenas proporções na composição química da crosta terrestre, embora se apresente em grandes concentrações nas águas subterrâneas. (CONCEIÇÃO et al., 2009 p. 73).

Elevadas concentrações de cloretos nas águas podem ter origem na falta de proteção dos poços, na pouca distância entre o poço e uma fossa, considerando que $58,4 \%$ dos poços estão a uma distância de até 20 metros de uma fossa (Tabela 3) e em outras fontes pontuais como na deposição a céu aberto das águas usadas.

As elevadas concentrações de cloretos encontradas no poço P6 (Tabela 6) em todas as amostras analisadas podem ter origem em uma fonte pontual de contaminação por cloreto de sódio $(\mathrm{NaCl})$. Este sal foi depositado em grandes quantidades em uma torre de transmissão de rádio clandestina localizada próximo ao poço. $O$ cloreto de sódio quando dissolvido libera íons cloretos $\left(\mathrm{Cl}^{-1}\right)$ que são lixiviados até o lençol freático contribuindo dessa forma, com as elevadas concentrações de

Geografia Ensino \& Pesquisa, v. 16, n.3 p. $77-92$, set./dez. 2012

Qualidade da água e fatores de contaminação de poços rasos na área urbana de Anastácio(MS) $721,1 \mathrm{mgL}^{-1}$ (valor mínimo) e 1.038,3 $\mathrm{mgL}^{-1}$ (valor máximo) superiores a 3 e 4 vezes, respectivamente, ao VMP de $250 \mathrm{mgL}^{-1} \mathrm{em}$ água para consumo humano.

As concentrações médias de dureza total, alcalinidade total e cloreto (Figura 7A) não sofreram influência da sazonalidade. A dureza total apresentou valores mais elevados no $V / 08$, e reduzidos nas demais estações, a alcalinidade manteve-se praticamente constante nas quatro estações e 0 cloreto apresentou a menor concentração no l/08 e aumentou nas duas últimas estações V/09 e l/09. 
Figura 7 - Valores médios das variáveis dureza total, alcalinidade total e cloreto (A) e pH e condutividade elétrica (B) por estação analisada.

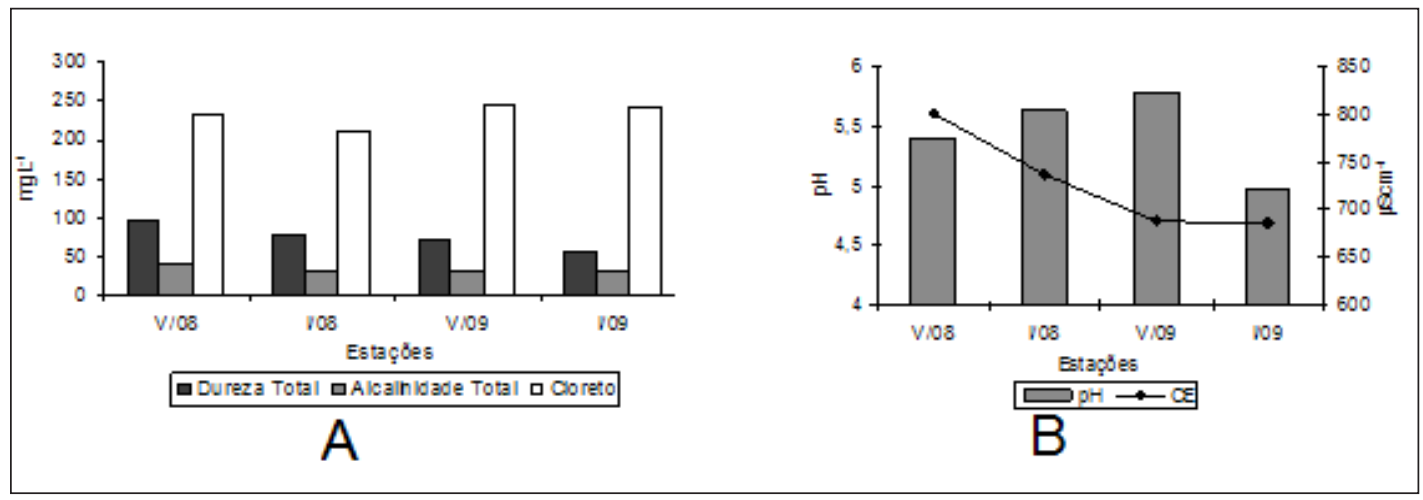

Fonte: pesquisa de campo (2009)

Os valores de $\mathrm{pH}$ em todas as amostras apresentaram-se na faixa ácida inferior a 6 , com exceção do poço 9 (Vila Flor) do 4 e 12 (Centro), portanto, fora do intervalo permitido de 6,0 a 9,5 (BRASIL, 2004), para as águas destinadas para consumo humano.

A CE mede a capacidade dos sais dissolvidos e ionizados conduzirem a corrente elétrica, que pode estar relacionado com as concentrações dos íons cloretos $(\mathrm{Cl})$, cálcio $\left(\mathrm{Ca}^{+2}\right)$ e magnésio $\left(\mathrm{Mg}^{+2}\right)$ e outros íons dissolvidos na água, apresentou valores elevados nos poços que também apresentaram concentrações de cloretos elevadas como os poços 1 e 3 (Vila Umbelina), 10 e 11 (Vila Rodrigues), 6 e 8 (Vila Flor)e 4 e 12 (Centro).

As médias por estação dos valores de pH e de CE (Figura 5B) demonstram que estas variáveis a exemplo das demais analisadas, não sofreram influência da sazonalidade. $\mathrm{O}$ pH apresentou valor superior no V/09 e inferior I/09. ACE apresentou valor superior no V/08 reduzindo nas demais estações.

Em cidades como Anastácio as deficiências no abastecimento público de água tratada, leva a população de baixa renda a perfurar poços, como alternativa para suprir as necessidades de abastecimento e diminuir as despesas domésticas com a conta de água. Captadas em poços rasos e utilizadas sem tratamento, essas águas colocam em risco a saúde dos consumidores. Assim, verificouse que vários fatores podem ser responsáveis pela contaminação das águas de poços em áreas urbanas na cidade de Anastácio, tais como: falta de manutenção da estrutura do poço (caixa externa, tampa, parede interna, calçada no entorno); localização ou construção inadequadas, ausência de cobertura para proteger da chuva e do escoamento superficial; deposição de esgoto doméstico a céu aberto, depósito de lixo e a falta de condições higiênico-sanitárias no sistema de captação da água, a exemplo da utilização de baldes e latas reutilizadas, sem qualquer processo mínimo de desinfecção.

\section{Considerações finais}

Os poços analisados na cidade de Anastácio não apresentaram adequação dos fatores de proteção, tornando-os susceptíveis à contaminação externa de suas águas. Observou-se a predominância de fossas rudimentares ou negras, localizadas próximas dos poços, situação preocupante já que a área apresenta uma reduzida espessura do material inconsolidado, fato que facilita a ligação com as águas freáticas, tornando a área urbana de Anastácio um local suscetível à contaminação das águas que abastecem os poços rasos utilizados pela população.

A presença de contaminação por bactérias do grupo coliformes e por cloretos ocorreu em todas as amostras nas quatro estações analisadas, mesmo nos poços localizados no setor centro que possui melhor adequação de infraestrutura de saneamento básico bem como, uma maior cobertura do serviço de captação de esgoto sanitário público. Logo, fatores higiênico-sanitários referentes à construção e manutenção do poço podem ser determinantes para qualidade das águas.

Geografia Ensino \& Pesquisa, v. 16, n. 3 p. $77-92$, set./dez. 2012

Cappi, N.; Ayach, N. R.; Santos, T. M. B.; Guimarães, S. T. L.

ISSN 2236-4994

189 
A sazonalidade não influenciou no NMP100 $\mathrm{mL}^{-1}$ de bactérias bem como, nas concentrações médias das variáveis dureza total, alcalinidade total, cloreto, $\mathrm{pH}$ e CE. Os valores de $\mathrm{pH}$ em todas as amostras apresentaram-se na faixa ácida inferior VMP para as águas destinadas para consumo humano.

As elevadas percentagens de amostras com presença de bactérias, as concentrações de cloretos acima do VMP e a CE elevada nas águas dos poços da cidade de Anastácio, podem ter origem na ineficiência do sistema sanitário da cidade, na falta de diretrizes do poder público referente ao planejamento urbano-ambiental, correlacionadas às fontes de poluição pontuais e difusas e seus impactos diretos e indiretos, gerando riscos de contaminação para a população, vinculados ao consumo de água sem tratamento, captada em poços rasos, construídos em locais inadequados e sem critérios técnicos, assim como de outros mananciais atingidos por diferenciadas formas de poluição de recursos hídricos.

\section{Referências}

APHA, AWWA, WPCF - American Public Health Association. Standard Methods for the Examination of Water and Wastewater. 19 ed. Washington, 1995, p. 1268

AMARAL, L. A. Controle da qualidade microbiológica da água utilizada em avicultura. In: Marcos Macari, Água na avicultura Industrial. 1 ed. Jabuticabal:FUNEP, 1996. Cap. 7. p 93-117.

AMARAL, L.A. ROSSI JR. O. D.; NADER FILHO, A; SOUZA, M. C. I. de; ISA, H.. Água utilizada em suinocultura como fator de risco à saúde humana e animal. Arquivos Veterinária, Jaboticabal, SP, v. 21, n 1, p.41-46, 2005.

AMARAL. L. A.; NADER FILHO, A.; ROSSI JUNIO, O. D.; FERREIRA, F, L, A.; BARROS, L. S. $S$. Água de consumo humano como fator de risco à saúde em propriedades rurais. Rev. Saúde Pública. São Paulo. 2003, v.37, n.4, p 510 - 514.

AGÊNCIANACIONAL DE ÁGUAS - ANA. Panorama da Qualidade das Águas Subterrâneas no Brasil. Brasília: ANA, 2007. 113p.

AYACH, L. R. As condições socioeconômicas, o saneamento básico e a qualidade da água subterrânea em Anastácio(MS): aspectos relacionados à percepção ambiental. 2011. 222 p. Tese (Doutorado em Geografia) Instituto de Geociências e Ciências Exatas, Universidade Estadual Paulista - UNESP, Rio Claro-SP, 2011.

AYACH, L. R. Implicações sócio-econômicas e sanitárias na qualidade das águas freáticas da cidade de Anastácio-MS. 2002. 110 p. Dissertação (Mestrado em Geografia) Universidade Federal de Mato Grosso do Sul, Dourados, 2002.

AYACH, L. R; PINTO, A. L.; CAPPI, N.;GUIMARÃES, S. T. de L. Contaminação das águas subterrâneas da cidade de Anastácio-MS. CLIMEP, Rio Claro, V.4. n 1. Janeiro/junho/2009. p.5-26.

BRASIL. Ministério da Saúde. Portaria No 518, de 25 de março de 2004. DOU. № 59. Seção 1. p.266. Brasília-DF, de 26 de março de 2004.

Geografia Ensino \& Pesquisa, v. 16, n.3 p. 77 -92, set./dez. 2012

Qualidade da água e fatores de contaminação de poços rasos na área urbana de Anastácio(MS)
CALHEIROS, D. F.; OLIVEIRA, M. D. de. Contaminação de corpos d'água nas áreas urnaba de Corumbá e Ladário. ADM - Artigo de Divulgação na Mídia, Embrapa Pantanal, Corumbá-MS, n. 89, p.1-4. nov. 2006. Disponível em: <http://www.riosvivos.org.br/Noticia/Contaminacao+de+corpos $+d+$ aguatna+regiao+de+Corumba/9526>. Acessado em: 20 nov 2009.

CAPPI, N; CARVALHO, E. M. de; PINTO, A. L. Influência de uso e ocupação do solo nas características químicas e biológicas das águas de poços na bacia do córrego Fundo, Aquidauana, 
MS. In: SIMPÓSIO DE GEOTECNOLOGIAS NO PANTANAL, 1, 2006, Campo Grande. Anais... Campo Grande: Embrapa Informática Agropecuária/INPE, 2006, p. 38-46.

CAPPI, N; GENTIL, H.P.R.; SANTOS, T.M.B.; XAVIER, C. de A. N. Qualidade química e sanitária da bacia do córrego João Dias, Aquidauana/MS. In: XL Congresso Brasileiro de Engenharia Agrícola. Cuiabá. Anais CONBEA, 2011. 2011, p.1-9.

CONCEIÇÃO, F. T. da; CUNHA, R.; SARDINHA, D. de S.; SOUZA, A. D. G.; SINELLI, O. Hidrogeoquímica do Aquífero Guarani na área urbana de Ribeirão Preto (SP). Revista Geociências. São Paulo. v. 28, n 1, 2009. p.65-77.

D'AGUILA, P. S.; ROQUE, O, C da C.; MIRANDA, C. A. S.; FERREIRA, A. P. Avaliação da qualidade de água para abastecimento público do Município de Nova Iguaçú . Cad. Saúde Pública, Rio de Janeiro, 2000, v.16, n3. p. 791-798.

LEAL, A. S. As águas subterrâneas no Brasil: ocorrências, disponibilidades e usos. SIH/ANEEL/ MME; SRH/MMA. Estado das águas no Brasil 1999: perspectivas de gestão e informação de recursos hídricos, 1999. p. 139-164.

HARRIS, D. C. Análise Química Quantitativa. 6 ed. Rio de Janeiro: LTC. 2005. 876 p

NOGUEIRA, G.; NAKAMURA, C. V.; TOGNIM, M. C. B.; ABREU FILHO, A.; DIAS FILHO, B. P. Qualidade microbiológica de água potável de comunidades urbanas e rurais, Paraná. Ver. Saúde Pública. Rio de Janeiro, 2003. v. 37, n.2. p, 232-236.

MACIEL, M. R. R. Perfil sócio-econômico domiciliar da população de Anastácio-MS. 2006. 62 f. Trabalho de Conclusão de Curso (Especialização em Geografia) - Universidade Federal de Mato Grosso do Sul, Aquidauana, 2006.

PINTO, A. L. Saneamento básico e suas implicações na qualidade das águas subterrâneas da cidade de Anastácio-MS. 1998. 175 p. Tese (Doutorado em Geociência e Meio Ambiente) Instituto de Geociências e Ciências Exatas, Universidade Estadual Paulista UNESP, Rio Claro-SP, 1998.

SILVA, R. C. A.; ARAUJO, T. M. Qualidade da água do manancial subterrâneo em áreas urbanas de Feira de Santana (BA). Rev Ciência \& Saúde Coletiva. Rio de Janeiro. v 8, n4, 2003, p.1019-1028.

SOTO, F. R. M.; FONSECA, Y. S. K; RISSSETO, M.; AZEVEDO, S. S. de. ARINO, M. L. B; RIBAS, M. A.; MOURA, C. R.V.; MACHETTE, D. S. Monitoramento da qualidade da água de poços rasos de escolas públicas da zona rural do Município de Ibiúna/SP: parâmetros microbiológicos, físicoquímicos e fatores de risco ambiental. Ver. Inst. Adolfo Lutz. v.65. n.2. 2006. p.106-111

\section{Correspondência:}

Nanci Cappi - Universidade Estadual de Mato Grosso do Sul, Universidade Estadual de Mato Grosso do Sul, Unidade Universitária de Aquidauana. Rodovia Aquidauana/CERA, Km 12. Rural. Cep. 79200-000 -. Aquidauana, MS - Brasil

E-mail: nccappi@uems.br

Recebido em 24 de agosto de 2012.

Geografia Ensino \& Pesquisa, v. 16, n.3 p. $77-92$, set./dez. 2012

Revisado pelo autor em 29 de novembro de 2012.

Cappi, N.; Ayach, N. R.; Santos, T. M. B.; Guimarães, S. T. L.

Aceito para publicação em 30 de novembro de 2012. 